\title{
Modeling of the Impact of Migration Attractiveness on the Labor Migration Dynamics
}

\author{
Alexander A. Tarasyev ${ }^{1,}$ a), Jeenat B. Jabbar ${ }^{2, b)}$, Gavriil A. Agarkov ${ }^{1, c)}$ \\ ${ }^{1}$ Ural Federal University, 620002, Mira Street, 19, Ekaterinburg, Russia \\ ${ }^{2}$ Refugee and Migratory Movement Research Unit (RMMRU), The University of Dhaka, Sattar Bhaban (4th Floor), \\ 179, Shahid Syed Nazrul Islam Sarani, Bijoynagar, Dhaka-1000, Bangladesh

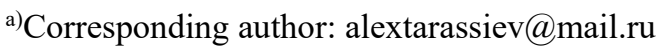 \\ b)jeenat.jabbar@gmail.com \\ c)g.a.agarkov@urfu.ru
}

\begin{abstract}
The analysis of migration processes shows the need to simulate the dynamics of migration flows, to describe the trends in the redistribution of labor in the current period and to forecast for the short term. To estimate and predict labor migration flows in terms of different levels of the labor markets development we elaborated a dynamic multi-factor migration model. The model takes into account the assumptions of the positional games theory, which allows predicting the behavior of a potential migrant, depending on an amount of socio-economic factors. We emphasize, that labor migration is one of the major factors in the development of the labor markets and in the redistribution of qualified workforce between them. To ensure sustainable development and economic growth of socio-economic systems the inflow of migrants into a region should correspond to the labor resources demand of the labor market. According to the model idea, potential migrants have full information about the difference in living and working conditions both in the countries of origin and attraction of migrants, which allows describing the decision-making process in the model. To improve the predictive accuracy of the model, we developed a method of assessing the migration attractiveness of the region, based on the principle of differentiation of regional economic systems by the level of socio-economic benefits. We obtain the synthetic parameter of the model, describing the migration attractiveness of the region, by combining socio-economic indicators in a relative form, reflecting the degree of development of the social system and the labor market in the region.
\end{abstract}

Keywords: dynamic modeling, games theory, positional games, Cobb-Douglas production function, labor market, labor migration, migration potential, migration attractiveness.

\section{INTRODUCTION}

Assessment and modeling of migration processes are necessary to ensure the possibility of improving the state policy of planning, aimed at the provision of services and stabilization of regional labor markets due to the impact on the levels of migration flows. When modeling social and economic processes, there is a need for complete, reliable information about the considered processes, otherwise we obtain a decrease in the predictive accuracy of the main model parameters.

When constructing dynamic models for description and prediction of migration processes it is necessary to note the debatable nature of the consequences of internal migration, and, therefore, it is difficult to make the optimal management decision to improve the quality of life in the region under consideration. Traditionally, in migration models, researchers combine data on the unemployment rate in the regions, the total number of vacancies, the average monthly wage and the annual number of migrants as the resulting factors of attracting and displacing migrants. At the same time, most of the models take into account on the provisions of behavioral economics rational economic behavior of the individual.

When considering internal migration at the regional level, the main incentive for starting migration is the lack of vacancies with the necessary income level, which allows describing the migration of the most active younger group

International Conference of Numerical Analysis and Applied Mathematics ICNAAM 2019

AIP Conf. Proc. 2293, 120004-1-120004-4; https://doi.org/10.1063/5.0027185

Published by AIP Publishing. 978-0-7354-4025-8/\$30.00 
of migrants. Thus, the person first seeks to minimize their losses from lack of work, which is a factor of displacement of migration, and, second, to maximize the expected profit after migration to get a higher level of income in another region, which is a factor of attraction.

\section{THEORETICAL FRAMEWORK}

The neoclassical theory of migration it assumes on the presence of free competition and a perfect market of production factors. The main idea of this concept is the international difference in the levels of wages, manifested in the functioning of labor markets. In terms of this approach, migration depends on a rational decision of the individual, taken based on complete and accurate information about the situation in the labor market, but it does not take into account the problems of unemployment and the cost of moving [4]. The difference between the wages of potential migrants and the local population in the country of migration attraction is an incentive for migration, due to the uneven distribution and low efficiency of production factors in these countries. At the same time, the difference in salary levels should be sufficient to cover the costs of relocation $[2,6]$.

Unit-labor cost is the most important factor in determining the price level in a closed economy [3]. Because of insufficient demand for manufactured goods, unemployment may rise. In a positive economic state, nominal wages are rising in line with the upward trend in labor productivity, as well as the Central Bank's inflation target, growthoriented discretionary monetary policy and counter-cyclical fiscal policy. Countries with large labor reserves relative to capital have low equilibrium market wages, while countries with limited labor reserves relative to capital have high wages, as evidenced by the interaction of labor supply and demand curves. As a result, wage differentials result in workers receiving low wages in high-wage countries in the country. In the case of full employment, a linear relationship between wage differentials and migration flows is predicted [1].

The aim of the neoclassical theory is to maximize the behavior of agents and flexible wages, which, using the forces of supply and demand, cleans the market and leads to equilibrium. A person continues to look for work if the expected income is less than or equal to the cost of the search. When a person finds a job with a higher salary, migration begins. Since the alternative is cheaper, it is not optimal to accept the first job offer. In accordance with the econometric model of E.S. Lee, presented in the framework of the push-and-pull theory, different groups of factors characterize each territory of migrants' arrival and departure [5]. These factors can have holding, attracting and pushing properties for migration and determine the arrival and departure of migrants. At the same time, the degree of impact and the level of coverage of the population differentiate migration factors. Economic factors are among the factors pushing out in the econometric model. These factors include unemployment, low income and high taxes, social and political factors, including poverty, discrimination, war and restrictions on freedom of conscience and religion, the factor of unfavorable natural and climatic conditions. The attractive factors for the destination area of migration include high level of economic development, higher incomes, security and access to the labor market.

Representatives of the institutional school of economics pay special attention to the study of the migration policy of the state, since the state is the most significant regulator of migration flows. Institutional economics focuses on a broader study of the interaction between social institutions and the market, while traditional institutionalism emphasizes the legal basis for the functioning and development of the economy. Within the framework of institutionalism, the state and state institutions acting as a regulator of migration flows are considered as elements of an Autonomous structure with certain goals and interests, and seeking to maximize the usefulness of labor resources [8].

The sociologist Douglas Massey [7] proposed the synthetic theory of migration, also known as the theory of migration networks. This theory explains international migration by the predominance of financial relations in nonmarket societies. Massey included in the basis of this theory the provisions of the classical theory of migration. According to Massey's theory, when deciding on migration and choosing a country for migration, an employee faces the problem of incomplete information about working conditions in other countries. The solution to this problem is possible using by migration networks, which present a set of interpersonal links between migrants, former migrants and potential migrants.

\section{MIGRATION ATTRACTIVENESS ESTIMATION}

We estimate the degree of attractiveness of the region for migration based on the author's method using the basic equation (1) and take into account in the model in the form of the resulting coefficient $a_{j}$ for each region of attraction of migration [9]: 


$$
a_{j}=\frac{P_{j}}{N_{j}},
$$

where $P_{j}$ is the synthetic coefficient, reflecting positive factors, which increase the migration inflow; $N_{j}$-synthetic coefficient, reflecting negative factors, reducing the migration flow into a region.

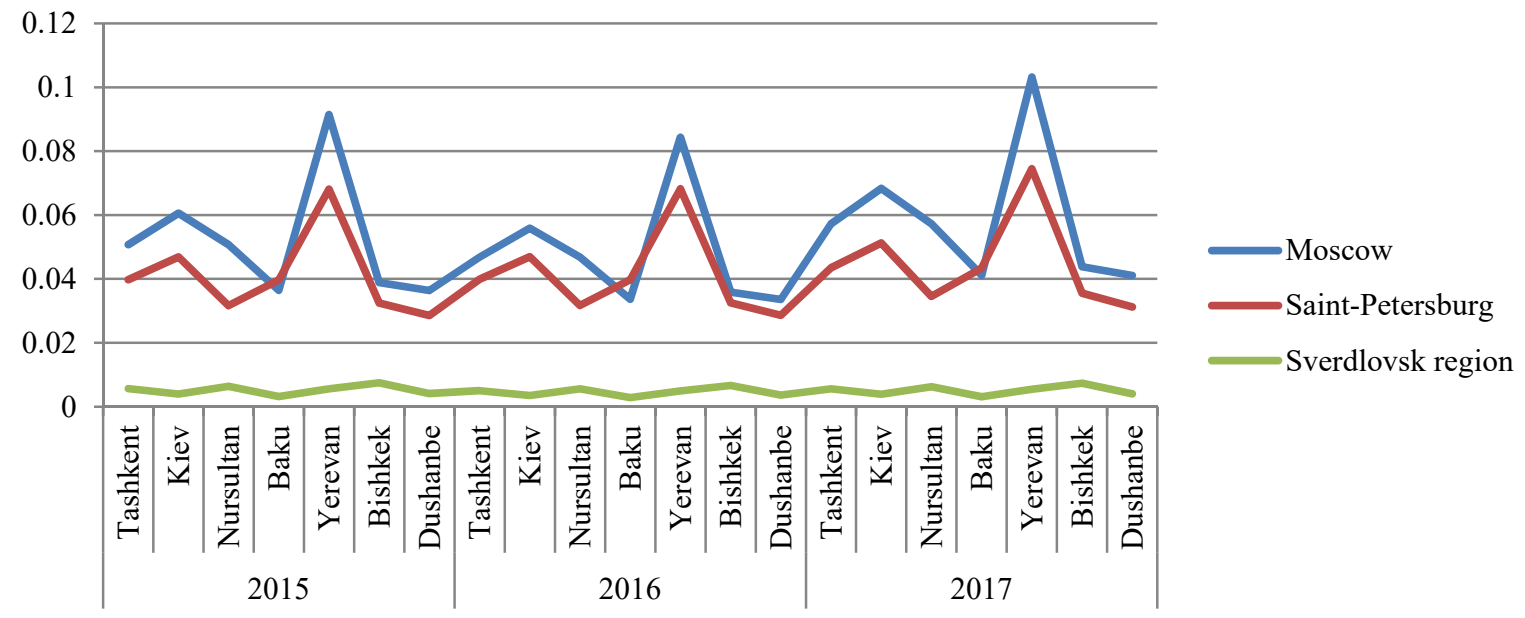

FIGURE 1. Migration attractiveness estimation.

$$
P_{j}=A_{P} \cdot S h_{j}^{\alpha} \cdot S a_{j}{ }^{\beta} .
$$

where $S h_{j}$ is the share of migrants in the region of migration destination;

$S a_{j}$ - coefficient reflecting the average monthly wage in the region relative to the average monthly wage in the country;

$A_{P}$ - calibrating coefficient reflecting positive factors considered implicitly in the model.

$$
N_{j}=A_{N} \cdot\left(\frac{M_{i j}}{M_{i J}}\right)^{\eta} \cdot C r_{j}^{\mu} .
$$

where $M_{i j} / M_{i J}$ - financial costs of the migrant for moving relative to the average for the country as a whole; $\mathrm{Cr}_{j}$ - is the coefficient, reflecting the crime situation in the region relative to the national average;

$A_{N}$ - calibrating coefficient reflecting negative factors considered implicitly in the model.

\section{LABOR MIGRATION DYNAMICS}

The model takes into account the assumption that there are no barriers to labor migration. The model allows describing migration between countries with visa-free regime. Taking into account the specifics of the functions describing the dynamics of wage levels depending on the influx of migrants, this model simulates an increase in the level of competition in the centers of migration attraction and a decrease in competition in the countries of departure. Taking into account the above main criteria, we developed a dynamic equation to describe the process of migration from the country of departure $i$ to the region of attraction $j$ at the time $t$ :

$$
x_{i j}(t+1)=x_{i j}(t)+a_{j} \cdot x_{i j}(t) \cdot \frac{P_{i}-x_{i j}(t)}{P_{i}} \cdot \frac{w_{j}(t)-w_{i}(t)-M_{i j} / N}{w(t)} d t,
$$

where $x_{i j}(t)$ denotes the migration flow, $M_{i j} / N$ denotes the migration costs, $P_{i}$ denotes the potential amount of migrants, $w_{i}$ and $w_{j}$ denotes the wage level in the country of origin and in region of attraction, respectively.

The labor market of migrants in developed models responds to the influence of external parameters, which possible by establishing the dynamics of natural growth and population decline, which increases the allowable limit of the forecast model. Forecasting the dynamics of the wage level in the region of attraction $j$ for the migration flow $x_{i}(t)$ at the time $t$ is carried out by the equation: 


$$
w_{j}(t)=w_{j}\left(t_{0}\right) \cdot \frac{E_{j}\left(t_{0}\right)+V_{j}\left(t_{0}\right)}{E_{j}\left(t_{0}\right)+U_{j}\left(t_{0}\right)+x_{j}(t)} .
$$

Model forecasting of wage dynamics in the country of origin $i$ for the migration flow $x_{i}(t)$ at the time $t$ is carried out in accordance with the function:

$$
w_{i}(t)=w_{i}\left(t_{0}\right) \cdot \frac{E_{i}\left(t_{0}\right)+V_{i}\left(t_{0}\right)}{E_{i}\left(t_{0}\right)+U_{i}\left(t_{0}\right)-x_{i}(t)} .
$$

The dynamics of the model reflects the impact of migration on competition in the labor market in the country of migration attraction (Fig. 1). Thus, if the salaries of immigrants will reduce, they will move to another region of attraction. In the case of low profits for migrants, immigration will stop and the trend will go in the opposite direction. The labor market of migrants in the developed model reacts to the impact of external parameters, at the expense of clarifying the dynamics of natural growth and population decline, as well as increasing the permissible limit of the forecast model.

\section{CONCLUSION}

According to the results of the analysis, we conclude that the dynamics of migration processes is directly dependent on the socio-economic conditions of the host territory. Indicators that reflect the situation in the labor market and financial indicators have the main impact on the fluctuations in migration growth. The strongest links in covariance matrices are between migration growth and average monthly wages, unemployment and the declared need for workers by the employment service. The sustainable development of the economic systems of the Russian regions requires a constant influx of skilled labor migrants. At the same time, it is necessary to optimize both the migration policy for obtaining labor resources with the necessary skills, and the concept of socio-economic development of the regions to maximize the efficiency of foreign labor resources.

In order to predict the flow of labor migrants in the framework of the concept of liberal development model, we developed a dynamic game model of labor migration, which determines the value of migration flows in the labor market through the introduction of two types of functions to assess the level of wages of migrants. Applying the model of migration attractiveness assessment, we identified the most attractive regions for migration and built a short-term forecast of the development of interregional migration processes. These models provide the construction of a scenario for the development of migration processes necessary for the sustainable development of systems of regional labor markets, so that it is possible to predict effective labor migration at the regional level.

\section{ACKNOWLEDGEMENTS}

The work was supported by Act 211 Government of the Russian Federation, contract № 02.A03.21.0006.

\section{REFERENCES}

[1] Borjas G.J. (2009). The Analytics of the Wage Effect of Immigration. NBER Working Paper, №14796.

[2] Harris J.R., Todaro M.P. (1970). Migration, Unemployment and Development: A Two- Sector Analysis. The American Economics Review, Vol.60. Is. 1. pp. 126-142.

[3] Herr H. (2008). The Labour Market in a Keynesian Economic Regime: Theoretical Debate and Empirical Findings. Cambridge Journal of Economics, Vol. 3, Is. 5, pp. 949-965.

[4] Hicks J.R. (1932). The Theory of Wages. London: Macmillan, 2nd ed., 1963.

[5] Lee E.S. (1966). A Theory of Migration. Demography, Vol. 3, No. 1, 47-57.

[6] Lewis W.A. (1954). Economic Development with Unlimited Supplies of Labor. The Manchester School, Vol. 22, No. 2, pp. 139-191.

[7] Massey D. A. (2002). Synthetic theory of international migration. World in the mirror of international migration, Vol. 10. pp. 143-153.

[8] Rutherford M. (2011). The Institutionalist Movement in American Economics, 1918-1947: Science and Social Control. Cambridge: Cambridge University Press, $410 \mathrm{p}$.

[9] Tarasyev, Alexandr A., Jabbar, Jeenat B. (2018). Dynamic Modeling of Labor Migration Impact on the Economic System Development. IFAC-PapersOnLine. Vol. 51(32). pp. 407-412. 